\title{
Schooling and Labor Market Impacts of a Natural Policy Experiment
}

\author{
Harry Anthony Patrinos* \\ The World Bank \\ hpatrinos@worldbank.org
}

\author{
Chris Sakellariou* \\ School of Humanities and Social Sciences \\ Nanyang Technological University, Singapore \\ acsake@ntu.edu.sg
}

\begin{abstract}
We use a nationally representative household survey to estimate returns to schooling in Venezuela from instrumental variables based on a supply-side intervention in the education market. These estimates apply to a subgroup of liquidity-constrained individuals, in the spirit of the local average treatment effect (LATE) literature. Returns to schooling estimates that apply to a subgroup of individuals affected by the policy intervention may be more interesting from a policy perspective than the return to the "average" individual. We use an instrument based on the 1980 education reform (the Organic Law of Education), which provided for nine years of compulsory basic education. Alternative estimates using father's education as an instrument are also obtained in an attempt to derive high and low estimates of returns to schooling in Venezuela. The estimates are consistent with recent findings suggesting that the effect of education, at least for certain subgroups affected by policy intervention, is as large as or larger than what is suggested by ordinary least squares estimates.
\end{abstract}

JEL Classification: J24, J31

Key words: Endogenous education, education reform, treatment effects, Venezuela

\section{World Bank Policy Research Working Paper XXXX, Month 2004}

The Policy Research Working Paper Series disseminates the findings of work in progress to encourage the exchange of ideas about development issues. An objective of the series is to get the findings out quickly, even if the presentations are less than fully polished. The papers carry the names of the authors and should be cited accordingly. The findings, interpretations, and conclusions expressed in this paper are entirely those of the authors. They do not necessarily represent the view of the World Bank, its Executive Directors, or the countries they represent. Policy Research Working Papers are available online at http:/lecon.worldbank.org.

\footnotetext{
* The views expressed here are those of the authors and should not be attributed to their respective employers. The authors received useful comments from George Psacharopoulos and Emiliana Vegas.
} 


\section{Introduction}

The rate of return to schooling has been of special interest from the standpoint of public policy, as the large number of past theoretical and empirical studies shows. Recent empirical studies that rely on theoretical advances that improved the understanding of crucial endogeneity and heterogeneity issues in the returns to education literature have almost exclusively used data from developed countries. However, from a policy perspective, evidence on developing countries would be valuable in assessing the effectiveness of education policies, especially when the focus of the policy maker is a section of the population, such as those who are liquidity constrained. As the interest in economics moves away from the effect of policies on the average individual and toward their effect on subsections of the population, research on returns to schooling in developing countries needs to focus on identifying the effects of education initiatives (such as compulsory schooling reforms, free education at certain levels, and accessibility to schools) on the disadvantaged, rather than the average individual.

A variety of empirical studies, mainly for developed countries, have used supplyside institutional features of the education system (such as compulsory schooling laws and accessibility of schools, among others) as instruments in instrumental variables (IV) estimations of the returns to schooling. The main finding is that such estimates of returns to schooling are typically larger than ordinary least squares (OLS) estimates. Card (2001) interprets this finding as suggesting that the marginal returns among the loweducation subgroups (which are typically affected by supply-side interventions) tend to be relatively high, reflecting their high marginal costs of schooling rather than low ability. 
In the presence of individual heterogeneity, OLS estimates are subject to traditional ability bias, due to the correlation between the ability component of the intercept of the earnings function and the marginal cost of schooling. If, in addition, there is heterogeneity in the slopes of the earnings function across individuals, individuals with a higher return to schooling have an incentive to acquire more schooling, resulting in upward-biased estimates of returns from an OLS regression. This endogeneity bias (also known as comparative advantage bias), is larger when the comparative advantage incentives are more important. On the other hand, errors in the measurement of the schooling variable would lead to a downward bias in the OLS estimate of the returns to schooling. Instrumental variables estimates in the presence of measurement error in the schooling variable are consistent, provided that the measurement error encountered is a classical one - schooling variable measured with additive random errors. If the measurement error does not satisfy the classical assumptions, then IV estimates will be biased either upward or downward (Kane and others 1999).

In using the IV method to measure the "true" effect of education" using crosssectional data, one needs an observable covariate that affects schooling but is uncorrelated with ability. Various variables on family background are frequently used. However, they are not expected to meet the requirement that they are uncorrelated with ability (among other possible reasons, due to inter-generational effects). Recently,

\footnotetext{
${ }^{1}$ As stated later on in this paper, one cannot talk of "the causal" effect of schooling from IV; different instruments (such as policy based instruments) result in different interpretations of the return estimate.
} 
supply-side sources of identifying information, such as various types of education reform, are increasingly sought after.

Considering one or more observable variables, $Z i$ (such as exposure to different education system regimes) and assuming that there is heterogeneity in the returns to schooling (affecting the slope of the earnings function, in addition to the intercept), consistent estimation of the average return to schooling requires the assumption that $Z i$ is independent of individual ability and the reduced form schooling residual (Heckman and Vytlacil 1999). If these conditions are not satisfied, then one must be careful in interpreting the instrumental variables estimates. In particular, and borrowing terminology from the literature on "treatment" effects, violation of these restrictive assumptions does not allow interpreting the IV estimates as the average "effect of treatment on the treated" (Heckman 1997). Furthermore, it may not be of particular interest to estimate the average return to education, as changes in education policies tend to target only certain population subgroups.

In this study, we interpret the IV results from using supply-side intervention and parent background instruments along the lines of the local average treatment effect (LATE) theoretical and empirical literature (see, for example, Imbens and Angrist 1994; Angrist, Imbens and Rubin 1996; Ichino and Winter-Ebmer 1998). In this context, IV estimates of the returns to schooling using, say, a compulsory education reform as instrument, would be interpreted as the average return to schooling for an individual who acquired an additional year of education as a result of the reform. This LATE would be 
different from either the effect of the reform on the random person, or its effect on the "treated."

There are very few studies for developing countries dealing with the issues surrounding the endogeneity of education and the implications of estimating returns to education from instrumental variables; exceptions are the studies by Maluccio (1997) and DuFlo (2001). Maluccio's study for the Philippines uses distance to the nearest high school as the main instrument (in some specifications supplemented with parental education and wealth). His study, however, uses panel data from Bicol region in the rural Philippines (one of the poorest in the country and, therefore, not representative) and relies on 250 or less observations for estimation of returns to schooling from instrumental variables. DuFlo (2001), on the other hand, uses a set of unique data and examines the effects of the schooling construction programs in Indonesia on education and earnings. Using the variation in schooling generated by the policy as instrumental variables, she generates estimates of economic returns to education ranging from 6.8 to 10.6 percent.

\section{Education in Venezuela}

The issue of free, public and compulsory education at the primary level in Venezuela first arose during the independence struggle. Simon Bolívar - the liberator of Bolivia, Colombia, Ecuador, Panama, Peru and Venezuela - having lived in France, was greatly influenced by the French educational system (such as the centralization and rigid structure of curricula), and issued a series of decrees concerning free education. The real beginning of free public education, however, did not come until 1870 , when then President Antonio Guzmán Blanco issued a decree in which he recognized compulsory 
elementary mass education as the responsibility of the national, state and local governments. But these ambitious beginnings came to an abrupt halt (http://reference.allrefer.com/country-guide-study/).

The return of democratic government in 1958 brought leaders committed to improving both the quantity and the quality of educational opportunities. In fact, it is generally acknowledged that it was only after 1958 that the ideals and goals of Guzmán Blanco began to be systematically pursued.

At least six years of primary school were compulsory until 1980 in Venezuela, when the Organic Law of Education was passed. This law provided for compulsory preschool education and nine years of basic education. Basic education consisted of nine years of compulsory schooling for children 6 to 14 years of age. For those continuing their education, the system offered two years of diversified academic, technical and vocational study at a senior high school, which could be followed by various types of higher education - junior college, university or technical institute.

Overall, Venezuela was among the most literate of the Latin American countries. The literacy rate among Venezuelans 15 years of age and older was 88 percent as early as in 1985. The government distributed training materials such as books and tapes throughout the country in an effort to encourage those who could read and write to assist illiterates in acquiring these skills. 
Venezuela's education system, as measured by the number of schools, teachers and size of enrollment, expanded rapidly in the 1970s and 1980s. Enrollments at all levels increased substantially, as did the numbers of schools and teachers at each level. Primary enrollments rose by over 30 percent and secondary by over 50 percent, while university-level enrollments nearly doubled, the latter a reflection not only of population growth but also of the opening of new schools and the easing of entrance requirements.

It is the 1980 reform which extended compulsory schooling from 6 to 9 years that is used here as the natural policy experiment. Compulsory schooling is thus used as the instrument in the subsequent analysis.

\section{Methodology and Diagnostic Testing}

Methodology. Within the general returns model, and given an instrument, $Z i$, the coefficient, $b i$, is meant to capture the individual idiosyncratic gain and has a population mean, $b_{0}$. Using IV estimation, even in the homogeneous returns model, we need the instrument to satisfy the orthogonality conditions; that is, that the instrument is uncorrelated with ability and the error term.

In the heterogeneous model, however, satisfying the orthogonality conditions is not enough. An additional property is required; namely, that for the treated, the instrument $Z$ is not correlated with the individual-specific component of the return, $b i$ (conditional on the observable regressors). Then we can recover the conditional effect of the treatment on the treated (ATT). However, the additional assumption is strong: while 
allowing for heterogeneous returns, $b i$, it requires schooling decisions to be unrelated to these individual gains (for a detailed discussion, see Blundell and others 2003).

When $\beta$ varies in the population, the return to schooling is a random variable and there is a distribution of causal effects, and different causal effects answer different questions. There are various ways to summarize this distribution of returns and, in general, no single statistic will capture all aspects of the distribution. Different summary measures include the average treatment effect (ATE), the treatment on the treated (TT), and treatment on the untreated (TUT). With heterogeneous returns, however, when individuals (partially) anticipate $\beta$, none of the treatment parameters identifies the "causal effect" of education.

Consider a model with two potential outcomes with respect to earnings $\left(\ln Y_{0}\right.$ and $\left.\ln Y_{1}\right)$, a vector of individual characteristics $(X)$ and potential outcomes generated by two random variables $\left(\mathrm{U}_{0}, \mathrm{U}_{1}\right)$ instead of one (common coefficient model). Following Hecknam and Vytlacil (1999, 2000) and Carneiro, Heckman and Vytlacil (2003):

$$
\ln \mathrm{Y}_{1}=\mu_{1}\left(\mathrm{X}, \mathrm{U}_{1}\right) \text { and } \ln \mathrm{Y}_{0}=\mu_{0}\left(\mathrm{X}, \mathrm{U}_{0}\right) .
$$

Enrollment in school is determined by the rule:

$$
\mathrm{S}=1 \text { if } \mu_{\mathrm{S}}(\mathrm{X}, \mathrm{Z})-\mathrm{Us}>0
$$

where $\mathrm{Z}$ is a vector of instrumental variables that influence the decision to enroll in school but not the potential outcomes. In the above, $\mathrm{Z}, \mathrm{X}$ are observed, while $\left(\mathrm{U}_{1}, \mathrm{U}_{0}, \mathrm{Us}\right)$ are unobserved, and the vector $\mathrm{Z}$ may include components of $\mathrm{X}$. 
Heckman and Vytlacil (2000; 2004) and Carneiro, Heckman and Vytlacil (2003) show how, under certain assumptions, the conventional IV estimates of returns to schooling relate to various treatment parameters and what policy questions IV estimation answers. The required assumptions are: (a) $\mu_{\mathrm{S}}(\mathrm{Z})$ is a non-degenerate random variable conditional on $\mathrm{X}$, which postulates the existence of a variable or set of variables that are in Z but not in X; (b) the distribution of U's is absolutely continuous; (c) $\left(U_{0}, U_{1}, U s\right)$ is independent of $\mathrm{Z}$ conditional on $\mathrm{X}$; (d) $\ln \mathrm{Y}_{0}$ and $\ln \mathrm{Y}_{1}$ have finite first moments. This is necessary for the definition of the mean parameters; and (e) $1>\operatorname{Pr}(\mathrm{S}=1 \mid \mathrm{X})>0$, which ensures that, at least in very large samples for each $X$ there will be individuals with $S=1$ as well as individuals with $\mathrm{S}=0$.

Besides the above testable assumptions, we need that the monotonicity restriction is satisfied. Given the events: $\mathrm{D}_{1 \mathrm{i}}=\left\{\mathrm{S}_{1 \mathrm{i}} \mid \mathrm{Zi}=1\right\}$ and $\mathrm{D}_{0 \mathrm{i}}=\left\{\mathrm{S}_{1 \mathrm{i}} \mid \mathrm{Zi}=0\right\}$, this requires that the instrument has the same directional effect on all those whose behavior it changes (i.e., $\left[D_{1 \mathrm{i}} \geq \mathrm{D}_{0 \mathrm{i}}\right]$ or $\left[\mathrm{D}_{1 \mathrm{i}} \leq \mathrm{D}_{0 \mathrm{i}}\right]$. This restriction is not testable, and its validity needs to be argued in the context of a particular application (Imbens and Angrist 1994).

Vytlacil (2002) shows that the model of equations (1) and (2), along with the above conditions is equivalent to the local average treatment effect (LATE) model of Imbens and Angrist (1994). Heckman and Vytlacil $(1999,2000)$ show that, under the stated conditions, the various treatment parameters are different weighted averages of the marginal treatment effect (MTE), where the weights sum up to one. 
Consider now a policy related instrument (such as one based on compulsory schooling). Compulsory schooling is frequently viewed as an ideal instrument (Angrist and Krueger 1991). However, when returns are heterogeneous, and when individuals making decisions about schooling act on this heterogeneity of returns, using the compulsory schooling instrument identifies only one of the possible treatment parameters; namely, the return to persons who decide to enroll only because of the policy change. Different policies, therefore, define different instrumental variables. It is useful to note, however, that if the instrument is the same as the policy being studied and the policy is exogenously imposed, the instrument can identify the effect of the exogenously imposed policy on the outcome being studied.

Diagnostic Testing. In testing the relevance and validity of instruments we essentially test that the instruments are correlated with the included endogenous variable(s) and orthogonal to the error process. The degree of correlation to the endogenous variables is easily tested by examining the fit of the first-stage regression after the included instruments are "partialled-out" (Bound and others 1995) and the F-test associated with it. If the explanatory power in the first stage is positive but, nevertheless, weak, then this is cause for concern (Staiger and Stock 1997; Baum and others 2003). In order to ascertain the independence of instruments from the unobservable error process, with an overidentified equation and given $\mathrm{L}$ instruments, one needs to test the corresponding orthogonality conditions arising from the L instruments using tests such as Sargan's (1958) statistic - a special case of the J-statistic of Hansen (1982) -, and in the presence of heteroskedastic errors, a "robust" Sargan's statistic. However, all the equations that are estimated in this paper are exactly identified. 
Finally, in testing for the consequences of employing the estimation method of instrumental variables (test of the endogeneity or exogeneity of regressors), one acknowledges the trade-off between a possibly biased and inconsistent OLS estimator and the higher asymptotic variance of the IV estimator. The test employed here is the Durbin (1954)-Wu (1973)-Hausman (1978) version of the Hausman statistic, using the OLS estimate of the error variance, as opposed to the IV estimate. ${ }^{2}$

\section{Data and Results}

Data. We use cross-sectional data from the 2000 Encuesta de Hogares por Muestro conducted by the National Statistical Office of Venezuela (OCEI). The working sub-sample is of male children of the head of household, working for wages and between the ages of 15 and 65 . The use of only male wage and salary earners, as in some other studies, was decided in order to avoid complications due to gender issues. Using only children of the head of household allows the inclusion of father's education and/or occupation in the earning function specifications.

The dichotomous instrument, $Z i$, arising from the 1980 compulsory education reform was constructed by identifying the age in year 2000 (year of the survey) of those individuals who would have been affected by the reform. Given the year of initiation of the reform, affected individuals $(Z i=1)$ are taken to be those who in year 2000 were in the 15-32 age bracket. Experimentation showed that a dichotomous instrument thus defined

${ }^{2}$ Under the null hypothesis both estimates are consistent, but the OLS estimate is more efficient. Furthermore, the chosen flavor of the test has the additional advantage of performing better when the instruments are weak (Staiger and Stock 1997; Baum and others 2003). 
correlates better with schooling, compared to using different cutoff points. Similarly, the use of a dichotomous instrument, thus defined, in the IV regressions results in higher precision of the schooling coefficient estimates, compared to definitions using a different cutoff point.

Estimation and interpretation of results. Preliminary evidence on the time trends of the returns to schooling in Venezuela, using OLS, seems to document falling returns to schooling until the mid-1990s, followed by slightly increasing returns thereafter (Patrinos and Sakellariou 2004). OLS estimates of overall returns to an additional year of schooling were about 8 percent in 2000 .

The estimated (OLS) schooling equations are presented in Table 1. In column (1) the covariates are only the binary "compulsory schooling" dummy and the trend in secondary enrollments in Venezuela. Column (2) includes other covariates but omits age and its square. Finally, column (3) includes all covariates. The results show that, after controlling for age and its square, as well as the trend in secondary enrollments and other characteristics, individuals (male children of the head of household) who were affected by the reform, consistently, have one more year of schooling, and the beneficial effect does not distinguish between family backgrounds. These results suggest that the "monotonicity" assumption is satisfied. One should also note, however, that if the identification assumption - namely that there is no other major reason why the cohorts affected by the reform would have different earnings than cohorts which are not affected, except for their having higher years of schooling (after controlling for a quadratic in age 
and the other control variables) - this will lead to a bias in the estimated returns to education.

Table 1: Schooling Equations, Venezuela, 2000

\begin{tabular}{|c|c|c|c|}
\hline Variable & (1) & (2) & (3) \\
\hline Age & - & - & $\begin{array}{c}0.448 \\
(6.1)\end{array}$ \\
\hline $\mathrm{Age}^{2}$ & - & - & $\begin{array}{l}-0.007 \\
(5.9)\end{array}$ \\
\hline Caracas & - & $\begin{array}{l}1.021 \\
(6.5)\end{array}$ & $\begin{array}{l}0.962 \\
(6.2)\end{array}$ \\
\hline Married & - & $\begin{array}{l}1.275 \\
(7.1)\end{array}$ & $\begin{array}{l}1.199 \\
(6.6)\end{array}$ \\
\hline Father's years of education & - & $\begin{array}{c}0.175 \\
(17.5)\end{array}$ & $\begin{array}{c}0.174 \\
(17.5)\end{array}$ \\
\hline "Reform" dummy & $\begin{array}{l}1.243 \\
(7.7)\end{array}$ & $\begin{array}{l}1.363 \\
(7.5)\end{array}$ & $\begin{array}{l}0.964 \\
(3.4)\end{array}$ \\
\hline $\begin{array}{l}\text { Secondary Enrollments } \\
\text { ('00 of thousand) }\end{array}$ & $\begin{array}{c}0.003 \\
(11.4)\end{array}$ & $\begin{array}{c}0.003 \\
(12.2)\end{array}$ & $\begin{array}{l}0.0001 \\
(0.1)\end{array}$ \\
\hline Father White Collar & - & $\begin{array}{l}1.074 \\
(2.9)\end{array}$ & $\begin{array}{l}1.013 \\
(2.7)\end{array}$ \\
\hline "Reform"* Father White Collar & - & $\begin{array}{l}0.483 \\
(1.2)\end{array}$ & $\begin{array}{l}0.505 \\
(1.2)\end{array}$ \\
\hline Constant & $\begin{aligned} & 4.838 \\
&(16.8)\end{aligned}$ & $\begin{array}{l}2.895 \\
(9.5)\end{array}$ & $\begin{array}{l}1.156 \\
(1.6)\end{array}$ \\
\hline $\begin{array}{l}\mathrm{R}^{2} \text { Adj. } \\
\text { F-value }\end{array}$ & $\begin{array}{l}0.030 \\
68.4\end{array}$ & $\begin{array}{c}0.206 \\
143.8\end{array}$ & $\begin{array}{c}0.213 \\
117.2\end{array}$ \\
\hline $\mathrm{N}$ & 4,411 & 3,859 & 3,859 \\
\hline
\end{tabular}

Source: Encuesta de Hogares por Muestro

Note: $t$-values in parentheses

The estimation results for standard earnings functions using OLS are presented in Table 2. Following standard practice, age is used instead of potential experience, as experience may be endogenous. Using OLS, the rate of return estimates for an additional year of schooling is 6 percent in the standard specification and 5.1 percent when, in addition, father's years of education enters the equation. 
Table 2: Returns to Education from OLS Estimates: Venezuela, 2000

\begin{tabular}{lcc}
\hline Variable & $(1)$ & $(2)$ \\
\hline Years of Schooling & 0.060 & 0.051 \\
& $(19.6)$ & $(15.6)$ \\
Age & 0.065 & 0.068 \\
& $(8.7)$ & $(9.1)$ \\
Age $^{2}$ & -0.0007 & -0.0008 \\
& $(6.2)$ & $(6.4)$ \\
Log hours worked & 0.434 & 0.433 \\
& $(15.5)$ & $(15.6)$ \\
Years of education of head & - & 0.013 \\
& & $(5.6)$ \\
Constant & 8.535 & 8.474 \\
& $(60.1)$ & $(59.8)$ \\
$\mathrm{R}^{2}$ Adj. & 0.247 & 0.254 \\
$\mathrm{~N}$ & 3,103 & 3,103 \\
\hline
\end{tabular}

Source: Encuesta de Hogares por Muestro

Note: t-values in parentheses

The IV estimation results, using the education reform and parental instruments, are presented in Table 3. The sample consists of male children of the head of household. In columns (1) and (2) the reform instrument is used alone; in column (2), father's years of education is an additional regressor. In column (3) the only instrument used is father's years of schooling completed. In the next few paragraphs, before discussing the IV estimation results, we present the framework for interpretation of the results.

Theory suggests that schooling choices are determined from a cost-benefit calculation, given alternative choices (see Angrist and Krueger 2001). Assuming heterogeneity in ability and schooling costs (for a discussion, see Card 2001; Ichino and Winter-Ebmer 1998; Angrist, Imbens and Rubin 1996; Imbens and Angrist 1994), consider the education reform of 1980 as instrument (labeling it $Z i$ ) which affects a subset of individuals in the sample. Denoting individual $i$ 's marginal return to schooling by $\beta i$, the probability limit of the IV estimator using instrument $Z i$ is:

$$
\operatorname{Plim} \beta_{Z i}=\operatorname{Cov}\left[\log y_{i}, Z_{i}\right] / \operatorname{Cov}\left[S_{i}, Z_{i}\right]
$$


or,

$$
\begin{gathered}
P \lim \beta_{Z i}=E(\log Y i \mid Z i=1)-E(\log Y i \mid Z i=0) / E(S i \mid Z i=1)-E(S i \mid Z i=0) \\
=\mathrm{E}_{\mathrm{gp}}\left(\beta_{\mathrm{gp}} \Delta \mathrm{S}_{\mathrm{gp}} \mid \mathrm{Z}\right) / \mathrm{E}_{\mathrm{gp}}\left(\Delta \mathrm{S}_{\mathrm{gp}} \mid \mathrm{Z}\right),
\end{gathered}
$$

with expectations taken over the joint distribution of the characteristics of the subgroups $(g p)$

With heterogeneity in both marginal returns to schooling and marginal costs of schooling, the optimal amount of schooling and the marginal return to schooling differs across individuals, with the probability limit of the IV estimator given above determined by the weighted effects of the marginal returns to schooling of the various subgroups.

Assuming the existence of subgroups (of different size) with various abilitydiscount rate combinations, that is, less well-off with high ability, well-off with low ability, and so on, if it can be determined which subgroup's schooling decision is mainly affected by the reform (nine years of compulsory schooling), the IV estimate of returns to schooling using the education reform instrument could be considered a consistent estimate of the return for that group of compliers. Here it is argued that such a subgroup will mainly consist of liquidity constrained individuals (who probably are of relatively low ability), who would have chosen the lower level of education without the reform. The size of the group affected by the reform may be quite large, given that in a developing country the proportion of liquidity constrained individuals is expected to be large. 
Returns estimated using this instrument and attributed to such a group of individuals are expected to be fairly high, compared to returns that could be attributed to other subgroups of individuals with different average characteristics.

In search of an alternative subgroup with different characteristics, consider parents' education as instruments (in this case, father's years of completed education). It can be argued that predominantly those who are less liquidity constrained (and of below average ability) will be compliers; that is, they will change (increase) their level of schooling, since they may overcome their learning difficulties due to their family background (see Ichino and Winter-Ebmer 1998). On the other hand, those from such a family background who are of above average ability would have acquired more education even without highly educated parents (always takers); there may, however, be some compliers among those from such a family background who are liquidity constrained but are of high ability, although most are expected to be never-takers.

As previously stated in the literature, using parental background instruments is likely to bias the average return to schooling upwards because, along with any independent causal effect of parental background on earnings, it is also expected that ability persists across generations. Therefore, although unaffected by the classical measurement error in the schooling variable, the probability limit of the IV return estimate is:

$$
\mathrm{P} \lim \beta_{\mathrm{F}} \approx \beta_{\mathrm{gp}}+\text { Bias. }
$$


Here F stands for the family background instruments used. The potential bias is positive, due to the direct causal effect of parental background on earnings. The true estimate of returns for this subgroup, which is expected to be lower than the one from using the "reform" instrument, is, therefore, expected to be even lower, further increasing the spread of estimates using different sets of instruments.

With heterogeneous returns, therefore, the IV estimator using a binary treatment instrument (such as one based on an education policy reform), identifies the effect on those who ordinarily would not have obtained more schooling but did so as a result of the policy change.

In columns (1) and (2) of Table 3, we instrument for schooling using the binary "reform" instrument. The estimate of the returns to one additional year of schooling is approximately 12 percent in both columns (1) and (2), that is, close to double the corresponding OLS estimate, confirming the expectation of a high rate of return estimate. Based on Hausman tests, the hypothesis that the OLS and IV estimates differ is accepted at levels of significance of about 10 percent.

Turning to column (3) of Table 3, IV estimates are derived using father's years of completed schooling. The estimate of the return to schooling for the affected subgroup in the specification is now 9.5 percent, about 2.5 percent lower compared to that of the affected subgroup in the specification using the reform instrument, but still significantly higher than the corresponding OLS estimate. Hausman tests easily reject the hypotheses that the OLS and IV estimates do not differ. 
Table 3: Returns to Education from IV: Venezuela, 2000

\begin{tabular}{|c|c|c|c|}
\hline & $\begin{array}{c}\text { (1) IV: } \\
\text { Compulsory education }\end{array}$ & $\begin{array}{c}\text { (2) IV: } \\
\text { Compulsory education }\end{array}$ & $\begin{array}{l}\quad \text { (3) IV: } \\
\text { Father's years } \\
\text { of education }\end{array}$ \\
\hline \multicolumn{4}{|l|}{ Variable } \\
\hline Years of Schooling & $\begin{array}{l}0.119 \\
(3.0)\end{array}$ & $\begin{array}{l}0.125 \\
(2.4)\end{array}$ & $\begin{array}{c}0.095 \\
(13.0)\end{array}$ \\
\hline Age & $\begin{array}{l}0.035 \\
(1.7)\end{array}$ & $\begin{array}{l}0.033 \\
(1.3)\end{array}$ & $\begin{array}{c}0.047 \\
(5.7)\end{array}$ \\
\hline $\mathrm{Age}^{2}$ & $\begin{array}{l}-0.0003 \\
(1.0)\end{array}$ & $\begin{array}{l}-0.0003 \\
(0.7)\end{array}$ & $\begin{array}{l}-0.0005 \\
(3.5)\end{array}$ \\
\hline Log hours worked & $\begin{array}{l}0.442 \\
(14.7)\end{array}$ & $\begin{array}{l}0.442 \\
(14.4)\end{array}$ & $\begin{array}{l}0.439 \\
(15.4)\end{array}$ \\
\hline Years of education of head & - & $\begin{array}{l}0.009 \\
(0.6)\end{array}$ & - \\
\hline Constant & $\begin{array}{l}8.460 \\
(53.4)\end{array}$ & $\begin{array}{l}8.501 \\
(55.2)\end{array}$ & $\begin{array}{l}8.490 \\
(58.4)\end{array}$ \\
\hline $\begin{array}{l}\text { Centered } \mathrm{R}^{2} \\
\mathrm{~N}\end{array}$ & $\begin{array}{c}0.152 \\
3,103\end{array}$ & $\begin{array}{c}0.132 \\
3,103\end{array}$ & $\begin{array}{l}0.213 \\
3,103\end{array}$ \\
\hline $\begin{array}{l}\text { Partial } R^{2} \text { for excluded } \\
\text { Instruments in } 1^{\text {st }} \text { stage }\end{array}$ & 0.002 & 0.002 & 0.137 \\
\hline $\begin{array}{l}\text { F-test } \\
\text { [p-value] }\end{array}$ & $\begin{array}{c}8.3 \\
{[0.04]}\end{array}$ & $\begin{array}{l}8.3 \\
{[0.000]}\end{array}$ & $\begin{array}{l}703.2 \\
{[0.000]}\end{array}$ \\
\hline $\begin{array}{l}\text { Pagan-Hall Test for } \\
\text { Heteroskedasticity }\end{array}$ & 76.6 & 98.53 & 100.5 \\
\hline [p-value] & {$[0.000]$} & {$[0.000]$} & {$[0.000]$} \\
\hline Heteroskedasticity robust & Exactly & Exactly & Exactly \\
\hline $\begin{array}{l}\text { Over-identification } \\
\text { Statistic } \\
\text { [p-value] }\end{array}$ & Identified & Identified & Identified \\
\hline Hausman Endogeneity & 2.62 & 2.44 & 30.72 \\
\hline $\begin{array}{l}\text { Test } \\
\text { [p-value] }\end{array}$ & {$[0.105]$} & {$[0.118]$} & {$[0.000]$} \\
\hline
\end{tabular}

Source: Encuesta de Hogares por Muestro

Notes: z-values in parentheses

At least part of the difference in the rate of return between OLS and IV estimates using father's education as instrument may be attributed to the bias from using family background instruments. The true estimate of the return to an additional year of schooling using father's education as instrument may, therefore, be closer to the OLS estimate. 
Finally, we considered the combination of the "reform" instrument with it's interaction with father's education as a set of instruments ${ }^{3}$ (the main set of instruments in some other studies, such as in Denny and Harmon 2000). The problem with this combination of instruments is that the estimates are compromised, as the instrument set is driven by father's education (see also Card 2001). The estimate of the return to schooling is 9.5 percent, which is very close to the average obtained from hundreds of studies reviewed in Psacharopoulos and Patrinos (2004).

\section{Conclusion}

We have used a supply-side intervention in the education market in Venezuela capable of generating significant changes in schooling. Using an instrument based on this intervention, we generated estimates of the return to schooling which apply to a subgroup of mainly liquidity constrained individuals. Such estimates may be more interesting (at least from a policy perspective) and easier to identify than the return to the "average" individual. Such LATE estimates are particularly useful if they can be attributed to the subgroup identified in the experiment.

This evidence, using instruments based on the education reform as well as on father's education, is consistent with most recent (as well as earlier, see Griliches 1977) findings, suggesting that the causal effect of education is as big or bigger than what is suggested by OLS estimates.

\footnotetext{
${ }^{3}$ Results can be made available by the authors upon request.
} 
Instrumental variables estimates will vary depending on which instrument is used and estimates may vary widely when heterogeneity is important. What is important to recognize is that the nature of the effect of the instrument on the distribution of returns is critical in understanding the estimated coefficient, and may in times be useful in bounding the returns in the population. In addition, when the instrument used is the same as the policy being studied and the policy is exogenously imposed, the instrument can identify the effect of the exogenously imposed policy on the outcome being studied.

In this paper we followed a potentially promising approach (similar to that by Ichino and Winter-Ebmer 1999), where we looked for different instruments that are likely to affect different subgroups in the population, by assessing to which part of the returns distribution the complier groups belong.

In Venezuela, the returns to schooling based on OLS estimates are rather low. However, the IV estimates using the compulsory reform instrument seem to indicate that the impact of compulsory schooling may have been benefitial to those who are liquidityconstrained. Using natural policy experiments provides a useful assessment of the impact of education policies on the targeted groups.

Empirical evidence on developing countries, such as the evidence from this study, contributes to our understanding of the effect of education initiatives - which are part of a development policy agenda - on certain sections of the population, such as those who are liquidity-constrained. The evidence suggests that the returns to schooling for the subgroup of individuals affected by education reforms, such as compulsory schooling 
laws and decreases in schooling costs (which mainly affect liquidity constrained individuals) are significantly higher than the returns to the "average" individual. More broadly, development policies need to be properly evaluated, using appropriate control groups and experiments, including innovative approaches that take advantage of natural policy experiments that lead to data variation. 


\section{References}

Angrist, J. and G. Imbens. 1995. "Tow-Stage Least Squares estimation of Average Causal Effects in models with variable treatment intensity." Journal of the American Statistical Association 90: 431-442.

Angrist, J., G. Imbens and D. Rubin. 1996. "Identification of causal effects using instrumental variables." Journal of the American Statistical Association 91: 444455.

Angrist, J. and A. Krueger. 1991. "Does Compulsory School Attendance Affect Schooling and Earnings." Quarterly Journal of Economics 106: 979-1014.

Angrist, J. and A. Krueger. 2001. "Instrumental variables and the search for identification: from supply and demand to natural experiments." Journal of Economic Perspectives 15(4): 69-85.

Baum, C., M. Schaffer and S. Stillman. 2003. "Instrumental variables and GMM: Estimation and testing." Working Paper 545, Boston College, Department of Economics.

Blundell, R., L. Dearden and B. Sianesi. 2003. "Evaluating the impact of education on earnings in the UK: Models, methods and results from the NCDS." IFS Working Paper N0. 03/20.

Bound, J., D.A. Jaeger and R. Baker. 1995. "Problems with instrumental variables estimation when the correlation between the instruments and the endogenous explanatory variable is weak." Journal of the American Statistical Association 90: 443-450.

Card, D. 2001. "Estimating the returns to schooling: Progress in some persistent econometric problems." Econometrica 69(5): 1127-1160.

Carneiro, P., J. Heckman and E. Vytlacil. 2003. "Understanding what Instrumental Variables estimate: Estimating marginal and average returns to education." Working Paper, Stanford University.

DuFlo, E. 2001. "Schooling and labor market consequences of school construction in Indonesia: Evidence from an unusual policy experiment." American Economic Review 91(4): 795-813.

Durbin, J. 1954. "Errors in variables." Review of the International Statistical Institute 22: 23-32.

Griliches, Z. 1977. "Estimating the returns to schooling: Some econometric problems." Econometrica 45: 1-22. 
Hansen, L.P. 1982. "Large sample properties of generalized method of moments estimators.” Econometrica 50(3): 1029-1054.

Hausman, J. 1978. "Specification tests in econometrics." Econometrica 46(3): 262-280.

Heckman, J. 1997. "Instrumental Variables: A study of implicit behavioral assumptions used in making program evaluations." Journal of Human Resources 32: 441-462.

Heckman, J. and E. Vytlacil. 1998. "Instrumental variables methods for the Correlated Random Coefficient model: Estimating the rate of return to schooling when the return is correlated with schooling." Journal of Human Resources 33: 974-987.

Heckman, J. and E. Vytlacil. 1999. "Local Instrumental Variable and Latent Variable Models for Identifying and Bounding Treatment Effects." Proceedings of the National Academy of Sciences 96: 4730-4734.

Heckman, J. and E. Vytlacil. 2000. "Local Instrumental Variables," in C. Hsiao, K.Morimune and J. Powells, eds., Nonlinear Statistical Modeling: Proceedings of the Thirteenth International Symposium in Economic Theory and Econometrics: Essays in Honor of Takeshi Amemiya. Cambridge: Cambridge University Press: $1-46$.

Heckman, J. and E. Vytlacil. 2004. "Structural Equations, Treatment Effects and Econometric Policy Evaluation." Econometrica (forthcoming).

Ichino, A. and R. Winter-Ebmer. 1998. "Lower and upper bounds of returns to schooling." Center for Economic Policy Discussion Paper 2007, London.

Imbens, G. and J. Angrist. 1994. "Identification and estimation of Local Average Treatment Effects." Econometrica 62(2): 467-75.

Kane, T., C. Rouse and D. Steiger. 1999. "Estimating returns to schooling when schooling is misreported." Working Paper 419, Princeton University, Industrial Relations Section.

Maluccio, J. 1998. "Endogeneity of schooling in the wage function: Evidence from rural Philippines." Food Consumption and Nutrition Division Discussion Paper No. 54, International Food Policy Research Institute, Washington D.C.

Patrinos, H.A. and C. Sakellariou. 2004. "Economic volatility and returns to education in Venezuela: 1992-2002." Washington, DC: World Bank (processed).

Psacharopoulos, G. and H.A. Patrinos. 2004. "Returns to Investment in Education: A Further Update." Education Economics 12(2): forthcoming.

Sargan, J. 1958. "The estimation of economic relationships using instrumental variables." Econometrica 26(3): 393-415. 
Steiger, D. and J.H. Stock. 1997. "Instrumental variables regression with weak instruments." Econometrica 65(3): 557-586.

Vytlacil, E. 2002. "Independence, monotonicity, and Latent Index Models: An equivalence result." Econometrica 70(1): 331-41.

Wu, D. M. 1973. “Alternative tests of independence between stochastic regressors and disturbances." Econometrica 42(3): 529-546. 